\title{
ORIGINAL ARTICLE \\ Longitudinal employment outcomes of an early intervention vocational rehabilitation service for people admitted to rehabilitation with a traumatic spinal cord injury
}

\author{
G Hilton $^{1,2}$, CA Unsworth ${ }^{1,3,4,5}$, GC Murphy ${ }^{5}, \mathrm{M} \mathrm{Browne}^{1}$ and J Olver ${ }^{2,6}$
}

Study design: Longitudinal cohort design.

Objectives: First, to explore the longitudinal outcomes for people who received early intervention vocational rehabilitation (EIVR); second, to examine the nature and extent of relationships between contextual factors and employment outcomes over time.

Setting: Both inpatient and community-based clients of a Spinal Community Integration Service (SCIS).

Methods: People of workforce age undergoing inpatient rehabilitation for traumatic spinal cord injury were invited to participate in EIVR as part of SCIS. Data were collected at the following three time points: discharge and at 1 year and 2+ years post discharge. Measures included the spinal cord independence measure, hospital anxiety and depression scale, impact on participation and autonomy scale, numerical pain-rating scale and personal wellbeing index. A range of chi square, correlation and regression tests were undertaken to look for relationships between employment outcomes and demographic, emotional and physical characteristics.

Results: Ninety-seven participants were recruited and 60 were available at the final time point where 33\% (95\% confidence interval (Cl): 24-42\%) had achieved an employment outcome. Greater social participation was strongly correlated with wellbeing $(\rho=0.692)$, and reduced anxiety $(\rho=-0.522)$, depression $(\rho=-0.643)$ and pain $(\rho=-0.427)$ at the final time point. In a generalised linear mixed effect model, education status, relationship status and subjective wellbeing increased significantly the odds of being employed at the final time point. Tertiary education prior to injury was associated with eight times increased odds of being in employment at the final time point; being in a relationship at the time of injury was associated with increased odds of being in employment of more than 3.5; subjective wellbeing, while being the least powerful predictor was still associated with increased odds (1.8 times) of being employed at the final time point.

Conclusions: EIVR shows promise in delivering similar return-to-work rates as those traditionally reported, but sooner. The dynamics around relationships, subjective wellbeing, social participation and employment outcomes require further exploration.

Spinal Cord (2017) 55, 743-752; doi:10.1038/sc.2017.24; published online 14 March 2017

\section{INTRODUCTION}

For most people who experience a traumatic spinal cord injury (SCI), gaining or returning to durable employment is a significant achievement $^{1}$ and a measure of rehabilitation success. ${ }^{2}$ Reengagement in vocational roles has a positive influence on quality of life $^{3}$ and is held to be an important part of the adjustment process following injury. ${ }^{4,5}$ Despite the health-promoting nature of work ${ }^{6}$ and the vocational potential of this group, ${ }^{2}$ employment rates after injury generally remain very low. ${ }^{5}$ Where there has been no explicit vocational intervention, rates are typically quoted as being around $35-40 \%$ in developed nations, ${ }^{1,2}$ but often are far less. ${ }^{7}$ Previous literature reporting post-injury vocational achievement has focussed on calculating crude employment rates following SCI or exploring the relationship with physical function. ${ }^{5,8}$ Similarly personal factors relating to employment outcomes such as the individual's education, pre-injury worker role and psychological traits have been examined. ${ }^{8-10}$ Relatively little, however, is known about how the passage of time may influence employment outcomes, as well as the nature and extent of influence of possible effects of environmental factors such as access to social support, funding and compensation arrangements, the geographical area where the individual lives including amenities and infrastructure, and the use of vocational services. $^{1}$

The availability of novel forms of vocational interventions that are accessible, individualised and flexible, and are therefore capable of meeting the multifaceted rehabilitation requirements of people with SCI is needed. ${ }^{11}$ There is some evidence for the effectiveness of evidence-based supported employment (EBSE) for people with SCI, ${ }^{12}$ but it is limited to the US veteran population and for people who have lived with SCI for several years. Early vocational rehabilitation interventions targeting individuals soon after injury have shown potential for enhancing post-injury labour force participation. ${ }^{13}$ The

${ }^{1}$ Occupational Therapy Department, Central Queensland University, Melbourne, Victoria, Australia; ${ }^{2}$ Victorian Spinal Cord Service, Austin Health, Melbourne, Victoria, Australia; ${ }^{3}$ School of Health and Welfare, Jönköping University, Jönköping, Sweden; ${ }^{4}$ Department of Occupational Therapy, Curtin University, Perth, Western Australia, Australia; ${ }^{5}$ School of Public Health, La Trobe University, Melbourne, Victoria, Australia and ${ }^{6}$ Psychiatry, University of Melbourne, Melbourne, Victoria, Australia

Correspondence: G Hilton, Occupational Therapy Department, Central Queensland University, 120 Spencer Street, Melbourne, Victoria 3000 , Australia and Royal Talbot Rehabilitation Centre, 1 Yarra Boulevard, Kew, Victoria 3101, Australia.

E-mail: g.hilton@cqu.edu.au or gillean.hilton@austin.org.au

Received 16 October 2016; revised 2 February 2017; accepted 7 February 2017; published online 14 March 2017 
potentially crucial role of an early vocational service is also suggested by Krause, ${ }^{14}$ who noted that it can take time for people to reach their vocational potential following SCI, particularly if an early 'window of opportunity' is missed. Therefore, the specific aims of this study were (1) to explore employment outcomes at three follow-up time points for people who received Early Intervention Vocational Rehabilitation (EIVR); and, (2) to explore the relationships between employment outcomes over time and a variety of variables as described by the International Classification of Functioning, Disability and Health (ICF). ${ }^{15}$ These variables can be grouped as aspects of functioning (physical and pain), activities and participation (psychological, social participation, relationships, pre-injury education and pre-injury worker role) and contextual personal and environmental factors (emotional/wellbeing, social support, funding arrangement and where one lives).

\section{MATERIALS AND METHODS}

\section{Study design}

The current study was a longitudinal cohort design following a group of people who had received EIVR as part of the Spinal Community Integration Service (SCIS) attached to the Austin Hospital's SCI Rehabilitation Unit.

\section{Participants}

Participants eligible for recruitment to the study had all sustained a new traumatic SCI, were residents of the state of Victoria, Australia, of working age at the time of injury (between 15 and 65) and admitted for inpatient rehabilitation with the state's SCI trauma service between the years 2010 and 2013. Individuals were not eligible if they had a co-morbidity of significant brain injury or cognitive impairment or a lack of English limiting their ability to participate, and became ineligible if discharged to a high-level care facility or interstate destination.

All consecutive admissions of people with SCI who met the inclusion criteria were approached to participate in the study. All potential participants accepted and were enroled in the study $(n=97)$ early in their admission to inpatient rehabilitation. Baseline data (time point one) were collected for all participants at discharge from inpatient rehabilitation. Data were available for $74(76.3 \%)$ people at the second time point (12 month following discharge) and 60 $(61.9 \%)$ at the third and final time point (2+ year following discharge). Fourteen $(14.4 \%)$ people declined to participate in data collection at the final time point and $n=23(23.7 \%)$ were unable to be contacted ( 2 of whom were deceased). At least 2 individuals who declined to participate stated being 'too busy' because of being in ongoing employment. Figure 1 reports on the sample sizes and data collection at different time points. Demographic data of the participant cohort are available in Table 1.

\section{Intervention}

Upon recruitment, participants received EIVR as part of SCIS. The SCIS was implemented in 2010 to provide specialist support for 12 months to individuals with newly acquired SCI transitioning home after a period of hospitalisation and rehabilitation. The initiative was supported by a collaboration between the state government health department and the state motor accident social insurance scheme. The role of the SCIS focused on improved community integration, and enhanced vocational and quality of life outcomes. The service also acted as a specialist SCI resource for community providers who required extra support in working with people with a SCI. A core component of SCIS was the delivery of EIVR within 2-4 weeks of admission to inpatient rehabilitation.

The SCIS staffing comprised 15 individuals totalling $\sim 7$ full-time equivalent (FTE) positions, representing allied health (physiotherapy, occupational therapy and exercise physiology) (1.5 FTE), nursing and sexual health counselling (0.7 FTE), medical (0.1 FTE), vocational rehabilitation (1.0 FTE), leisure (0.4 FTE), formal peer support (0.9 FTE), psychosocial (1.0 FTE), building consultancy (0.2 FTE) and a programme manager (1.0 FTE). A predominant and unique feature was the recruitment of a VR professional to focus on enhancing the return to work (RTW) culture within the rehabilitation setting, to encourage early, positive expectations about work, ${ }^{5}$ and to provide vocational interventions to encourage and facilitate vocational pathways and employment outcomes. The VR professional was also responsible for providing education about EIVR to other members of SCIS and to the inpatient rehabilitation team. Theoretical underpinnings to SCIS work were drawn from the concepts of occupational performance, ${ }^{16}$ participation ${ }^{17}$ and community development. ${ }^{18}$ The service also drew on the experiences and knowledge of existing programmes in other states of Australia and New Zealand such as Spinal Outreach Service in New South Wales, ${ }^{19}$ Transitional Rehabilitation Program in Queensland ${ }^{20}$ and Kaleidoscope in New Zealand. ${ }^{21}$

A coordination team (a project coordinator and the SCIS programme manager) led the implementation of SCIS including the development and delivery of a training package to reinforce theoretical underpinnings and a consistent practice approach. The training sessions focused on building skills in the following: engaging and building a relationship with the individual with SCI, motivational interviewing, ${ }^{22}$ goal planning and community development. The training also included an introduction to vocational rehabilitation theory and practice, including guiding principles for an early intervention approach. ${ }^{23}$

The driving philosophy of EIVR was to instil the individual as early as possible, with a sense of hope and possibility about returning to or gaining work following SCI. The VR professionals from SCIS aimed to make initial contact with the individual within 2-4 weeks of admission to inpatient rehabilitation, unless advised otherwise by the inpatient treating team. Their role included acknowledging the vocational identity of the individual, forming a vocational plan and tailoring interventions to suit the person's goals and situation. Although outcomes such as study or volunteer work were legitimate achievements and considered an important part of the vocational pathway, the ultimate goal of EIVR was for the person to achieve a paid employment outcome. In doing so, there were no constraints on process nor timeline, recognising that each individual needed to assume his/her own journey of recovery, learning and adjustment post injury. A summary of the EIVR 'practice guidelines' is presented in Table 2. Every person who was enroled in the study was offered at least step one and two of the EIVR process.

\section{Measures}

Data collection occurred at three time points: discharge from inpatient rehabilitation (time 1); 12 months following discharge (time 2); and at least 2 years following discharge (time 3 ). Basic demographic and injury data were collected at baseline. This included age, gender, relationship status, neurological level of lesion (including American Spinal Injury Association impairment scale (AIS) definitions), impairment type (tetraplegia, paraplegia), compensation availability, where someone resided, living arrangement and estimates of care and support (hours of paid and unpaid care in a typical day). Information about where someone lived was then converted to a geographical area, or statistical local area (SLA), an Australian Standard of Geographical Classification. SLA can be used in Geographical Information Systems to analyse against other available government data such as area remoteness, area economics, labour force activity and ease of access to amenities. ${ }^{24}$ For simplicity, geographical area was dichotomised to 'regional' or 'metropolitan'. On aggregation, 'metropolitan' indicates a lower level of area remoteness and a higher level of area socio-economic status, labour force activity and ease of access to amenities.

Vocationally related data included pre-injury education background (highest level achieved), type of occupation (professional, manual labour and so on) and employment status ('employed' was defined as ' $\geqslant 1 \mathrm{~h}$ work in which you were paid' and was recorded from self-report as full time (that is, over $35 \mathrm{~h}$ per week), part-time variable, part-time fixed and also as a dichotomous variable, 'in the labour force' versus 'all others'). Any changes in demographic or injury data were noted at follow-up time points. Several self-rated standardised scales of psychosocial functioning were used as indices of rehabilitation progress at all three data collection points, as described in the following sections.

Numeric pain-rating scale. An 11-point numeric pain-rating scale was used as a measure of pain intensity where participants were asked to rate their experience of pain on a scale of $0-10$, (where 0 is 'no pain' and 10 is 'the 


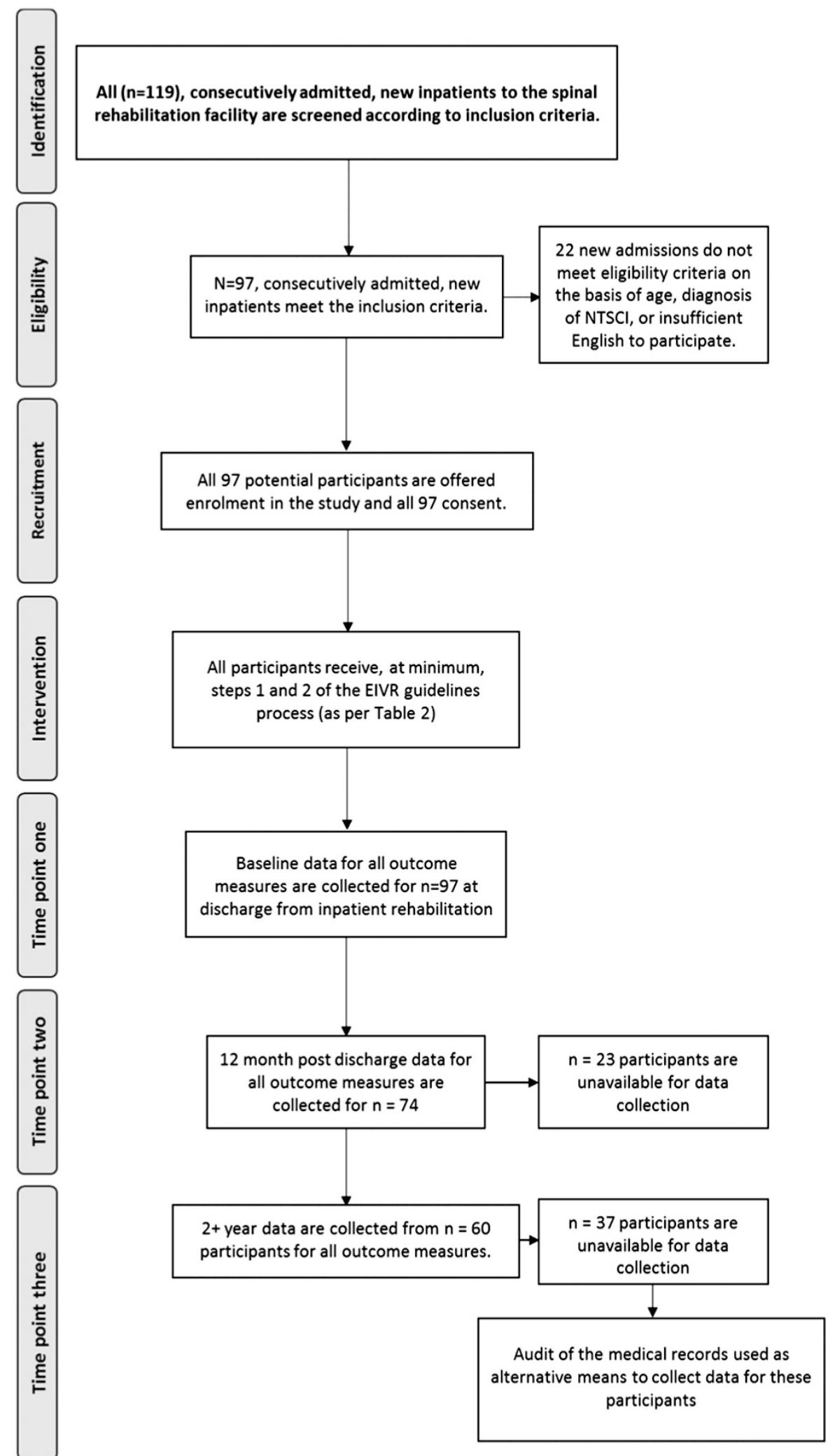

Figure 1 Flow chart of recruitment. A full colour version of this figure is available at the Spinal Cord journal online.

worst possible'). Numeric pain scales have demonstrated their validity as measures of pain by their strong association with other measures of pain intensity, as well as by their responsivity to treatments known to impact pain. ${ }^{25}$
Hospital anxiety and depression rating scale. The Hospital anxiety and depression rating scale (HADS) is a 14 question, 4-point, self-report rating scale designed to assess depressive and anxiety symptoms in patients with 
Table 1 Demographic data $(n=97)$

\begin{tabular}{|c|c|c|c|}
\hline & $N$ & Mean & s.d \\
\hline Age at injury (years) & 97 & 35.070 & 14.908 \\
\hline $15-45$ & 72 & & \\
\hline $46-65$ & 25 & & \\
\hline Sex & & $\%$ & \\
\hline Male & 79 & 81.4 & \\
\hline Female & 18 & 18.6 & \\
\hline \multicolumn{4}{|l|}{ Severity of SCI neurology } \\
\hline C1-C4 AIS A, B or C & 10 & 10.3 & \\
\hline C5-C8 $\mathrm{AlS}^{1} \mathrm{~A}, \mathrm{~B}$ or $\mathrm{C}$ & 23 & 23.7 & \\
\hline T1-S5 AIS A, B or C & 45 & 46.4 & \\
\hline AIS D any level & 19 & 19.6 & \\
\hline \multicolumn{4}{|l|}{ Impairment level } \\
\hline Tetraplegia & 43 & 44.3 & \\
\hline Paraplegia & 54 & 55.7 & \\
\hline \multicolumn{4}{|l|}{ Compensation status } \\
\hline Insured & 51 & 52.6 & \\
\hline Public/uninsured & 46 & 47.4 & \\
\hline Education level prior to injury & 96 & & \\
\hline Higher (tertiary) & 16 & 16.5 & \\
\hline Lower & 80 & 82.5 & \\
\hline Occupation type prior to injury & 78 & & \\
\hline Professional & 27 & 27.8 & \\
\hline Trade or unskilled & 51 & 52.6 & \\
\hline
\end{tabular}

Abbreviations: AIS, American Spinal Injuries Association impairment scale; SCl, spinal cord injury.

medical illness. Preliminary findings support the psychometric integrity of the HADS within an outpatient population with SCI. ${ }^{26}$ Separate subscale scores, ranging from 0 to 21, for depression (HADS-depression) and anxiety (HADS - anxiety) can be derived. Higher scores indicate greater psychological distress.

The personal wellbeing index. The personal wellbeing index (PWI) is a selfreport scale developed as a measure of subjective wellbeing and holds high cross-cultural validity. ${ }^{27}$ Part one can be used as a single-construct measure of global life satisfaction, or part two as a multi-item life satisfaction domain scale. The statements use an 11-point $(0-10)$ end-defined response scale addressing domains such as health, relationships, future security and personal achievement ${ }^{28}$ with a final score between 0 and 100 with higher scores indicating greater subjective wellbeing.

Spinal cord independence measure. The spinal cord independence measure (SCIM) measures self-care, respiration, sphincter management and mobility. It consists of 16 questions with a final score ranging between 0 and 100 (SCIMtotal), with higher scores indicating greater functional independence. SCIM is a reliable and valid measure of functional status for people with SCI. ${ }^{29}$

Impact on participation and autonomy. The impact on participation and autonomy (IPA) is a generic outcome measure designed for adults with a range of conditions. The english version ${ }^{30}$ contains 32 items that create five subscales —autonomy indoors, family roles, autonomy outdoors, social life and relationships, and work and education. Each subscale is averaged to produce a median score from 0 to 4 . In addition, a total 32-item score can be derived. A lower score on the IPA suggests greater perceived autonomy and participation. The questionnaire takes $\sim 20 \mathrm{~min}$ to complete and it can be self-administered. It has been found to be a reliable and valid instrument for assessing autonomy and participation in chronic disorders, including $\mathrm{SCI} .{ }^{31}$ As participants were inpatients at the time of the first data collection, the IPA was collected at the second and final time point only.

\section{Procedure}

Ethical approval for this study HREC/14/Austin/256 was obtained from the Hospital and University Human Research Ethics Committees. The authors certify that all applicable institutional and governmental regulations concerning the ethical use of human volunteers were followed during the course of this research.

The SCIS programme manager was responsible for screening eligible individuals for recruitment to the research and obtaining a signed informed consent form. This was done in close consultation with the inpatient treating team. A member of the SCIS was responsible for collecting measures with the participants at the first and second time points as documented above. At the second data collection (12 months following discharge from inpatient rehabilitation), formal involvement by the SCIS ceased. Participants were then contacted by mail and telephone to complete a further follow-up (third time point) at least 2 years after injury. Participants were offered a $\$ 20$ department store gift voucher to thank them for their time in completing the third round of data collection. Finally, an audit of medical records was undertaken as an alternative method of collecting basic data of the most recent report of employment status for people who did not complete the final data collection at $2+$ years following discharge.

\section{Analyses}

Initially $\chi^{2}$ analysis was used to test for systematic attrition bias. Differences between people who were included in the study but without 2+ year follow-up, and people who had $2+$ year follow-up were explored, on categorical variables of gender, age group, injury type, AIS group, pre-injury education level, preinjury occupation type, compensation status and geographical area for time point 1.

Descriptive statistics (means, s.d.) and comparison between the groups of 'in the labour force' or 'all others' were used. This included summarising key variables such as age, gender, compensation status, neurological level of injury, education, pre-injury employment type, geographical area, function (SCIMtotal), perceived pain (numeric pain-rating scale), psychological status (HADS —anxiety and depression), social participation (IPA subscales) and subjective wellbeing (PWI) at each time point using means and s.d.'s where applicable. Chi square analysis was used to test for differences between participants in/out of the labour force prior to injury and at the three time points post injury for the categorical variables of gender, age group, injury type, AIS group, pre-injury education level, pre-injury occupation type, compensation status and geographical area (statistical local area). Mann-Whitney $U$-test was used to compare years since injury in participants in/out of the labour force at the final time point.

The second research question investigated in the current study related to the identification of relationships between employment outcomes and variables described according to the ICF. Aspects of functioning included injury characteristics, physical status (SCIM-total) and pain (numeric pain-rating scale). Variables relating to activities and participation included psychological (HADS - anxiety and depression), social participation (IPA total), relationship status, pre-injury education and pre-injury worker role. Variables measured as contextual personal and environmental factors included subjective wellbeing (PWI), social support (IPA subscale social life and relationships), funding arrangement and geographical area (statistical local area) over the three time points.

Interdependence between the variables was determined with Spearman's correlation coefficient. As suggested by Craig et al. ${ }^{32}$, a dichotomised value for social participation was established using the mean score of the sample (IPA total). That is, values equalling the mean score or less will indicate high participation, and values greater than the mean will indicate low participation.

The main aim of the regression analysis was to investigate possible predictors of employment status in recovering patients. Owing to the relatively low ratio of participants to independent variables (IVs), each was treated in a separate regression model. This approach was taken because including all IVs and time 
Table 2 A summary of practice guidelines for EIVR

Process Timeline Tas

Establish relationship with individual First meeting inpatient rehabilitation setting

Establish vocational identity of individual

Explore vocational options

Establish vocational goals, commence vocational pathway

Within 2-4 weeks of admission to inpatient rehabilitation ( 6 weeks post injury)

Within inpatient setting or as required 1-6 months post injury

Within inpatient or outpatient setting or as required
2-12 months post injury

Within outpatient setting or as required When work ready
Service development role No set time frames

Tasks

Gather background demographic information including education and employment history

Liaise with inpatient team regarding pre-vocational activity

Identify relationship with pre-injury employer

Identify motivations and future aspirations

Exploration of vocational options, inclusive of retraining or return to study (RTS)

Career counselling

Facilitate contact/support to pre-injury employer

Facilitate connections with peer support

Facilitate connections with disability liaison officers at education facilities

Facilitate connections with community-based vocational rehabilitation providers

Assist in navigation of entitlements and government benefits associated with RTS,

retraining, job seeking and RTW

Provide expert advice, assistance with planning and practical guidance relevant to individual's situation.

For example: If vocational goal involved retraining or RTS, VR professional to offer community-based support such as joint visit to meeting with disability liaison

officer, environmental assessment of educational facility, or work with individual to identify and practice transport options.

For example: If vocational goal involved returning to work, VR professional to offer community-based support such as joint visit to workplace, meeting with human

resource officer or equivalent, environmental assessment of workplace, or work with individual to identify and practice transport options.

Job support

Worksite visit to assess both physical and social demands of the position and workgroup

Assessment/prescription workplace equipment and/or modifications

Assist in navigation of entitlements and government benefits associated with job seeking and RTW.

Development (in coordination with both the patient/client and the putative supervisor) of return-to-work plan

Facilitating/supporting workplace trials or industry experience

Post placement support (to ex-patients and family members, as well as to workplace co-workers and supervisors
Education to inpatient rehabilitation teams on importance of work in adjustment process and early intervention vocational rehabilitation role

Education of co-workers and supervisors at the workplace

Education to family and other relevant social supports and facilitating family-based problem solving, life planning

Referral/consultation/education to community-based vocational rehabilitation

providers

Education to health professionals

Meet with disability liaison officers at education facilities

Networking with local government, not-for-profit and private enterprises to establish possible employment links/opportunities

Education to funder
$\mathrm{X}$ IV interactions would result in an unacceptably high number of degrees of freedom in the model. Therefore, reported beta coefficients of these models do not reflect co-variation between predictors. Accordingly, a simultaneous multiple logistic regression was also conducted. Each model also included an effect for time (discharge, 1 year, 2+ years), and a time X IV interaction term. We employed generalised linear mixed effects models (GLMEs) with a binomial error distribution and a log link, ${ }^{33}$ to manage the repeated measurements and the binary response. Apart from the fixed effects, each GLME also included a random intercept for participant. All analyses were conducted in the $\mathrm{R}$ statistical programming environment. ${ }^{34}$ Data collected in the audit of medical records were included in this analysis and the GLMEs.

\section{RESULTS}

The mean duration of SCI at the final time point was $3.50 \pm 1.08$ years. Figure 1 demonstrates the sample sizes and data collection at different time points. Employment status was obtained for all participants at the third time point via self-report for study participants $(n=60)$, and from audit for non-respondents $(n=37)$. At the third time point, $n=32(33 \%, 95 \%$ CI: $24-42 \%)$ of the total cohort $(n=97)$ were in paid employment. Chi-square test for independence to examine attrition bias indicated no significant differences between the demographic characteristics of study participants and non-respondents at 
Table 3 Comparison of demographic data $(n=97)$ at time point 3 for people in labour force versus all others

\begin{tabular}{|c|c|c|c|c|c|}
\hline & $\begin{array}{l}\text { In labour } \\
\text { force }\end{array}$ & $\%$ & $\begin{array}{l}\text { Not in labour } \\
\text { force }\end{array}$ & $\%$ & $\begin{array}{c}\mathrm{P}- \\
\text { value }\end{array}$ \\
\hline $\begin{array}{l}\text { Years since injury, mean (s. } \\
\text { d.) }\end{array}$ & 3.32 & 1.16 & 3.58 & 1.04 & \\
\hline \multicolumn{6}{|l|}{ Age at injury (years) } \\
\hline $15-45$ & 24 & 24.7 & 48 & 49.5 & 1 \\
\hline $46-65$ & 8 & 8.2 & 17 & 17.5 & \\
\hline \multicolumn{6}{|l|}{ Severity of SCI neurology } \\
\hline C1-C4 AIS A, B or C & 2 & 2.1 & 8 & 8.2 & 0.42 \\
\hline C5-C8 AIS A, B or C & 9 & 9.3 & 14 & 14.4 & 0.43 \\
\hline T1-S5 AIS A, B or C & 17 & 17.5 & 28 & 28.9 & \\
\hline AIS D any level & 4 & 4.1 & 15 & 15.5 & \\
\hline \multicolumn{6}{|l|}{ Compensation status } \\
\hline Insured & 14 & 14.4 & 37 & 38.1 & 0.32 \\
\hline Public/uninsured & 18 & 18.6 & 28 & 28.9 & \\
\hline \multicolumn{6}{|l|}{ Education level prior to injury } \\
\hline Higher (tertiary) & 10 & 10.4 & 6 & 6.3 & $0.01^{*}$ \\
\hline Lower & 21 & 21.9 & 59 & 61.5 & \\
\hline \multicolumn{6}{|l|}{ Occupation type prior to injury } \\
\hline Professional & 11 & 14.1 & 16 & 20.5 & 0.56 \\
\hline Trade or unskilled & 16 & 20.5 & 35 & 44.9 & \\
\hline
\end{tabular}

Abbreviations: AIS, American Spinal Injuries Association impairment scale; SCI, spinal cord injury.

${ }^{*} P<0.05$ (2-tailed) for chi square.

the final time point, except for pre-injury education level $\chi^{2}((1, n=96)=6.5, P=0.005)$. Twenty-five $(78.1 \%)$ of those finally employed had been in full-time employment prior to their SCI, of whom $n=13(40.6 \%)$ returned to full-time employment ( $n=1$ on leave), and $n=12(37.5 \%)$ went to part-time employment. Of the $n=3$ who were part-time employed prior to injury, $n=1(3.1 \%)$ went into full-time employment post injury, and $n=2(6.3 \%)$ remained in part-time employment post injury. Four participants had not been employed prior to their injury and found part-time employment following.

Descriptive statistics and comparison between all categorical variables and the primary outcome measure of employment status are presented in Table 3, which shows that there were no significant differences between the two groups, 'in the labour force' and 'all others' across all categorical variables at the final time point, except for education level $\chi^{2}((1, n=96)=6.4, P=0.01)$. A Mann-Whitney $U$ test revealed no significant difference in the years since injury of those people 'in the labour force' $(\mathrm{Md}=3.1, n=32)$ and 'all others' ( $\mathrm{Md}=3.8, n=65), U=889.5, z=-1.156, P=0.248, r=-0.112$.

The relationship between personal characteristics at the different time points was investigated using Spearman's correlation coefficient. Correlations for all continuous and dichotomised categorical variables with the dichotomous variable of employment status ('in the labour force' versus 'all others') are shown for the final time point in Table 4.
Table 4 Spearman $\rho$ correlations between all predictor variables and employment status (in the labour force versus all others) at final time point

\begin{tabular}{lr} 
Measure & Employment status \\
\hline 1. Gender & -0.109 \\
2. Age at injury & 0.006 \\
3. Age group & -0.029 \\
4. Injury type (para/tetra) & -0.011 \\
5. Neurological level (AIS) & -0.137 \\
6. Funding status & 0.063 \\
7. Pre-injury education level & 0.181 \\
8. Occupation type prior to injury & 0.076 \\
9. Where living & 0.130 \\
10. Relationship status & 0.062 \\
11. HADS-Anxiety & -0.114 \\
12. HADS-Depression & -0.082 \\
13. Total SCIM & 0.096 \\
14. Total PWI & 0.238 \\
15. Total care hours & -0.119 \\
16. Numeric Pain-Rating scale & -0.177 \\
17. IPA Autonomy indoors & -0.061 \\
18. IPA Family roles & 0.131 \\
19. IPA Autonomy outdoors & -0.136 \\
20. IPA Social Life and Relationships & -0.196 \\
21. IPA Work and education & -0.023 \\
22. Total IPA & 0.010 \\
\hline
\end{tabular}

To include the total IPA score in analysis as a measure of social participation, the mean score in the current study of 61.11 (s.d. 21.03) was used to dichotomise this variable. Therefore, scores of 61 or below were used to indicate high levels of social participation $(n=33)$ and scores above 61 were considered to represent low levels of social participation $(n=28)$.

Across the three times points there were several strong, statistically significant correlations between variables. At time point $2+$ years, the dichotomised variable of social participation was positively associated with subjective wellbeing $\rho=0.692, n=60, P<0.0005$, and negatively associated with anxiety $\rho=-0.522, n=61, P<0.0005$, depression $\rho=-0.643, \quad n=61, \quad P<0.0005$ and pain $\rho=-0.427, \quad n=60$, $P<0.0005$. Higher levels of perceived participation and autonomy were correlated with high levels of subjective wellbeing, low anxiety and depression scores, and low rating of pain. The full correlation matrix between variables at the final time point is presented in Table 5 .

Table 6 shows odds ratios, beta coefficients and associated standard errors for the binomial GLMEs. Education status $(P<0.01)$, relationship status $(P<0.05)$ and Total PWI $(P<0.05)$ were reliably associated with being employed post injury. No time-varying effects were significant at the $P<0.05$ criterion. The most powerful predictor (holding a degree prior to injury) was associated with an eightfold increased odds of being employed at the follow-up point. Being in a relationship at the time of injury was another strong predictor, being associated with increased odds of being in employment of more than $350 \%$. General health and wellbeing scores at the time of discharge were associated with a significant, but much smaller, increase in the odds of post-injury employment $(\mathrm{OR}=1.8)$.

On the basis of the strength of their individual predictive ability, relationship status (at time point one), pre-injury education level and subjective wellbeing were entered into a logistic regression model over 


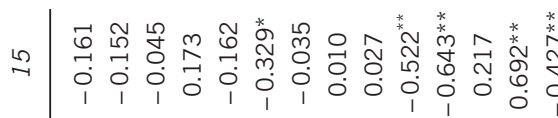

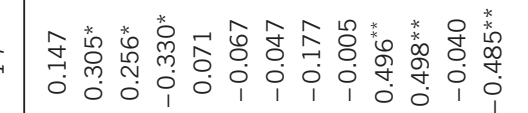

ชั

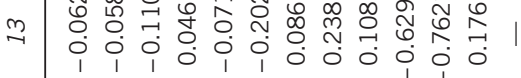

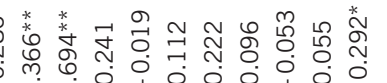

(2)

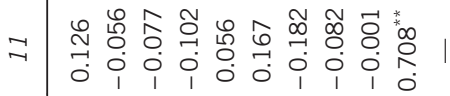

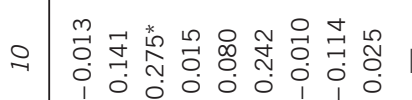

(1)

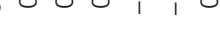

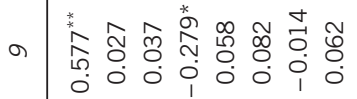

$\infty$

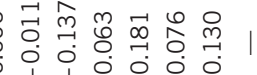

the different time points. The model for predicting a labour force outcome at the third time point was statistically significant, $\chi^{2}(3, N=79)=11.663, P=.009$. The model as a whole explained $13.7 \%$ (Cox and Snell $R^{2}$ ) and $18.9 \%$ (Nagelkerke $R^{2}$ ) of the variance in employment status, and correctly classified $68.4 \%$ of cases. When controlling for all other factors, the strongest and statistically significant predictor of being in the labour force in this model was being in a relationship, recording an odds ratio of 3.406 (CI: 1.197-9.697) $P=0.022$.

\section{DISCUSSION}

This paper described the development, implementation and results of early intervention vocational rehabilitation delivered as part of a hospital-led SCIS. It aimed to identify employment outcomes for the study cohort and the relationship between employment-related outcomes and various personal and environmental factors in the five years following injury. In this study, $33 \%$ of our cohort had returned to employment by the third time point. This post-injury employment rate is comparable to those of other studies, the rate being a slightly lower rate than that of Middleton et al. ${ }^{13}$ and a slightly higher rate than that of Ottomanelli et al. ${ }^{12}$ With respect to reliable predictors of post-discharge employment, three influential factors were identifiedpre-injury education, relationship status at time of injury and selfreported wellbeing.

The post-discharge employment rate observed from the current early intervention programme is comparable to that reported from the observational study by Middleton et al., ${ }^{13}$ who recently reported the outcomes of the delivery of their early vocational rehabilitation in an Australian acute and rehabilitation SCI setting when post-injury employment was assessed within one year post discharge. At case closure (median 3 weeks post discharge), $34.5 \%$ had an employment outcome. This rate is consistent with that quoted in aggregated research of $35-40 \% .^{2}$ However, Middleton et al.'s ${ }^{13}$ employment achievements were reached within a much shorter timeframe post injury than that is usually investigated. Although Middleton et al. has commenced the process of researching early vocational rehabilitation in Australia, similar programmes delivered into New Zealand acute spinal units since 2000, have been described but not been studied empirically. Hay-Smith et al. ${ }^{21}$ reported on the New Zealand early intervention vocational rehabilitation service, known as Kaleidoscope, and described its aim as nurturing positive expectations of future community participation after a SCI, believed to be an important precursor to employment outcome. ${ }^{5}$ Employment rates have reportedly increased since Kaleidoscope's inception ${ }^{21}$ but little detail regarding claimed increases has been reported. The research work led by Ottomanelli, ${ }^{12}$ Middleton, ${ }^{13}$ as well as Hay-Smith ${ }^{21}$ all suggest that vocational rehabilitation delivered early post SCI warrants further investigation, as does determination of whether vocational outcomes are sustained beyond 12 months.

In determining whether certain functions, activities, participation and contextual factors would increase the likelihood of achieving an employment outcome over the duration of this study, three independent variables of relationship status, pre-injury education level and subjective wellbeing were identified, from which some causality may be inferred. Of these three variables, relationship status and subjective wellbeing are the only 'modifiable' factors and therefore, consideration needs to be given to these during inpatient and outpatient rehabilitation, and to the potential role of both variables in influencing employment outcomes. For allied health and nursing staff, the finding with respect to relationship status has implications for the ways that patients' level of post-injury social support is monitored and, if need 
Table 6 Odds ratios, beta coefficients and associated standard errors for binomial GLMEs predicting employment status (in the labour force versus all others)

\begin{tabular}{|c|c|c|c|c|c|c|c|}
\hline & & \multicolumn{2}{|c|}{ Main effect } & \multicolumn{4}{|c|}{ Time interaction } \\
\hline & & $O R$ & $\mathrm{~B}(S E)$ & $O R$ & $\mathrm{~B}(S E)$ & $\mathrm{N}_{o b s}$ & $\mathrm{~N}_{\text {part }}$ \\
\hline \multicolumn{2}{|l|}{ Gender (female) } & 0.78 & $-0.25(0.77)$ & 0.59 & $-0.53(0.77)$ & 281 & 97 \\
\hline \multicolumn{2}{|l|}{ Age (46-65) } & 2.12 & $0.74(0.65)$ & 0.48 & $-0.53(0.60)$ & 281 & 97 \\
\hline \multicolumn{2}{|l|}{ Education (tertiary) } & $8^{* *}$ & $2.08(0.77)$ & 2.41 & $0.88(0.59)$ & 278 & 96 \\
\hline \multicolumn{2}{|l|}{ Location (urban) } & 0.91 & $-0.09(0.58)$ & 1.38 & $0.32(0.45)$ & 281 & 97 \\
\hline \multicolumn{2}{|c|}{ Finding status (uninsured) } & 2.27 & $0.82(0.58)$ & 1.55 & $0.44(0.46)$ & 281 & 97 \\
\hline \multicolumn{2}{|c|}{ Injury type (paraplegia) } & 0.84 & $-0.18(0.58)$ & 0.76 & $-0.28(0.45)$ & 281 & 97 \\
\hline \multicolumn{2}{|l|}{ Total PWI } & $1.8^{*}$ & $0.59(0.29)$ & 1.31 & $0.27(0.30)$ & 204 & 89 \\
\hline \multicolumn{2}{|l|}{ Total SCIM } & 0.96 & $0.45(0.32)$ & 1.57 & $-0.04(0.29)$ & 210 & 89 \\
\hline \multicolumn{2}{|l|}{ Total care } & 0.89 & $-0.12(0.26)$ & 0.74 & $-0.30(0.25)$ & 198 & 87 \\
\hline \multirow[t]{2}{*}{ (AIS) } & T1-S5 ABC & 1.92 & $0.65(0.68)$ & 0.66 & $-0.08(0.84)$ & 281 & 97 \\
\hline & AIS D & 0.66 & $-0.41(0.54)$ & 0.59 & $-0.65(0.67)$ & 281 & 97 \\
\hline \multicolumn{2}{|l|}{ Total IPA } & 3.49 & $1.25(0.85)$ & 0.32 & $-1.11(1.05)$ & 136 & 84 \\
\hline
\end{tabular}

${ }^{*} P<0.05,{ }^{* *} P<0.01$

Each row in the table corresponds to a separate regression model.

be, strengthened. In many areas of injury rehabilitation, social support has been shown to be associated with superior rehabilitation outcomes (see for example, Murphy and O'Hare ${ }^{35}$ ). Services to enhance the subjective wellbeing of those living with SCI have been extensively researched by Kennedy ${ }^{36}$ who has described programmes that reliably improve patient's coping effectiveness. Both of these areas of service provision seem worthwhile strengthening in any hospital-based rehabilitation programme.

Although research on social support is relatively limited in the SCI population, Murphy et al. ${ }^{37}$ found that practical social support was the most frequently reported contributing factor to enabling positive employment outcomes following SCI. This has been further supported by findings of Burns et al. ${ }^{38}$ who established that in a self-selected group of 83 men, greater perceived social support from significant others was related to higher employment outcome. Hence, further research to investigate the impact of environmental features such as financial as well as social support on employment outcomes achieved post SCI appears well warranted.

Finally, the impact of time as a factor related to employment outcomes must be considered. A consistent finding in reports of employment outcome is that employment rates increase over the first 10-15 years post injury. ${ }^{39,40}$ Krause $^{14}$ studied factors related to the length of time between onset of SCI and RTW in $n=259$ people who had returned to work post injury, and suggested that it can take time for an individual to reach full vocational potential, particularly if an early 'window of opportunity' is missed. Furthermore, Murphy argues that there is a clear need for vocational management as part of inpatient rehabilitation. ${ }^{23}$ In a modelling of employment trajectory in a cohort of $n=176$ with acute SCI, Ferdiana ${ }^{40}$ identified three distinct trajectories. The first encompassed no employment prior to injury and no employment for 5 years post injury (called 'no employment'), the second included employment prior to injury and an increasing chance of employment in the 5 years post injury (termed 'low employment') and the third covered employment prior to injury and steady employment within 5 years post injury (described as 'steady employment'). The study found that participants with secondary education were significantly more likely to gain steady employment outcomes versus low or no employment. This reinforces the value of VR including components such as retraining and education early after injury to potentially enhance opportunities for employment outcome, particularly for people with a likely trajectory of low or no employment.

Although the early return to employment following SCI was associated with higher subjective wellbeing, there was no relationship with other psychosocial outcomes. A relationship did exist for these variables with social participation. There was an association between higher levels of social participation with high levels of subjective wellbeing, low anxiety and depression scores, and low rating of pain. Although social participation was not a primary focus of this study, this finding is of interest given the known relationship between this variable and employment, ${ }^{32}$ and that Craig et al. ${ }^{32}$ posit that social participation is a measure of adjustment following SCI. The literature consistently reports that employment is health promoting; ${ }^{6}$ yet it might be that early return, although overall a positive step, is still fundamentally very difficult. At a practical level, there are many personal and environmental factors to be considered and addressed in the RTW process. This research may be capturing a period of change and uncertainty as one returns to work or gains post-injury work that initially counteracts the expected benefits of being a worker. It may be valuable to explore more thoroughly this complex dynamic, and the relationship of employment with social participation in future research, as was suggested by Craig et al. ${ }^{32}$

\section{Limitations and directions for further research}

The study as conducted had an obvious limitation in lacking a control group, but to the our knowledge, this is the first study of early intervention vocational rehabilitation that examines, longitudinally, predictors of employment outcome. When originally designing the 
study we planned to use a comparison group which would receive treatment as usual. However, for practical reasons owing to different funding arrangements with compensable and non-compensable clients, a suitable comparison group could not be assembled.

There was a drop-out rate of $n=37$ ( $38.1 \%$ of participants) over the three time points, resulting in a relatively small sample size by the final time point. This drop-out rate is equivalent to that reported by other similar longitudinal studies investigating this population. ${ }^{41}$ However, in this study, although 37 participants were lost to follow-up at the third time point, their employment outcomes were still able to be obtained through an audit of their ongoing medical record. When collecting data at time point 3 , there was a small proportion of people who declined to participate because of being 'too busy' owing to employment. These people may be 'happy workers' and unfortunately this data has not been captured.

Despite many similarities in the traumatic spinal cord-injured population throughout the world, ${ }^{42}$ the differences in local policy and service delivery create challenges in comparing or translating findings across countries and jurisdictions. However, the introduction of an early intervention approach to vocational rehabilitation could be applied to other settings, and is worthy of further investigation.

A further potential limitation to this study was the existing culture in the inpatient rehabilitation setting and the possible lack of willingness to embrace the new early vocational rehabilitation intervention. Education was provided to clinical staff in anticipation of this barrier, as historical experience has been that vocational rehabilitation has not been a priority focus of the inpatient rehabilitation setting. Murphy ${ }^{23}$ and Ottomanelli and Lind ${ }^{8}$ have previously recognised this same issue. Anecdotally, as staff became more familiar with the EIVR conversation and observed individuals achieving employment outcomes (including even returning to work although still participating in inpatient rehabilitation), the rehabilitation hospital culture became more positive and supportive over the duration of the study. This culture shift may well account for some of the variance in outcomes across the three time points.

An important follow-up to this research is to interview individuals about their experiences of seeking and gaining employment. Exploring the concepts of timing and adjustment in relation to returning to work, coupled with identifying influential environmental and personal factors could deliver further insights into understanding the complexity of returning to work for people following traumatic SCI. This work is currently underway.

\section{CONCLUSION}

This research explored employment outcomes for people receiving EIVR and the relationship between these and personal and environmental factors in the first $2-5$ years following injury. EIVR shows promise of delivering equivalent return to work rates to that reported in similar studies, earlier after injury, although it is premature to claim to have reliably demonstrated effectiveness of this intervention. Several factors were identified that appear facilitatory of employment outcome, including relationship status, subjective wellbeing and preinjury education. These and the relationship between social participation and employment outcomes are worthy of further investigation, particularly in relation to how they may support the return to, and maintenance of, employment in this population in the future. The findings of this study can inform clinical practice, particularly the importance of maintaining pre-injury relationships and subjective wellbeing to promote positive employment outcomes.

\section{DATA ARCHIVING}

There were no data to deposit.

\section{CONFLICT OF INTEREST}

The authors declare no conflict of interest.

\section{ACKNOWLEDGEMENTS}

We acknowledge the following people who contributed their time and knowledge to this study: the study participants, Lynne Panayiotis, Julie Wong, Pamela Beaumont and Belinda Rickard.

1 Trenaman L, Miller W, Escorpizo R. Interventions for improving employment outcomes among individuals with spinal cord injury: a systematic review. Spinal Cord 2014; 52: 788-794.

2 Young A, Murphy G. Employment status after spinal cord injury (1992-2005): a review with implications for interpretation, evaluation, further research, and clinical practice. Int J Rehabil Res 2009; 32: 1-11.

3 Manns PJ, Chad KE. Components of quality of life for persons with a quadriplegic and paraplegic spinal cord injury. Qual Health Res 2001; 11: 795-811.

4 Boschen KA, Tonack M, Gargaro J. Long-term adjustment and community reintegration following spinal cord injury. Int J Rehabil Res 2003; 26: 157-164.

5 Schonherr MC, Groothoff JW, Mulder GA, Schoppen T, Eisma WH. Vocational reintegration following spinal cord injury: expectations, participation and interventions. Spinal Cord 2004, 42: 177-184.

6 McKee-Ryan F, Song Z, Wanberg CR, Kinicki AJ. Psychological and physical well-being during unemployment: a meta-analytic study. J Appl Psychol 2005; 90: 53.

7 Putzke JD, Barrett JJ, Richards JS, Underhill AT, Lobello SG. Life satisfaction following spinal cord injury: long-term follow-up. J Spinal Cord Med 2003; 27: 106-110.

8 Ottomanelli L, Lind L. Review of critical factors related to employment after spinal cord injury: implications for research and vocational services. J Spinal Cord Med 2009; 32: 503-531.

9 Trenaman L, Miller WC, Querée M, Escorpizo R. Modifiable and non-modifiable factors associated with employment outcomes following spinal cord injury: a systematic review. J Spinal Cord Med 2015; 38: 422-431.

10 Lidal IB, Huynh TK, Biering-Sorensen F. Return to work following spinal cord injury: a review. Disabil Rehabil 2007; 29: 1341-1375.

11 Roels EH, Aertgeerts B, Ramaekers D, Peers K. Hospital- and community-based interventions enhancing (re)employment for people with spinal cord injury: a systematic review. Spinal Cord 2016; 54: 2-7.

12 Ottomanelli L, Barnett SD, Goetz LL. Effectiveness of supported employment for veterans with spinal cord injury: 2-year results. Arch Phys Med Rehabil 2014; 95: 784-790.

13 Middleton JW, Johnston D, Murphy G, Ramakrishnan K, Savage N, Harper R et al. Early access to vocational rehabilitation for spinal cord injury inpatients. J Rehabil Med 2015; 47: 626-631.

14 Krause JS. Years to employment after spinal cord injury. Arch Phys Med Rehabil 2003; 84: 1282-1289.

15 World Health Organization Toward a Common Language for Functioning, Disability and Health. WHO: Geneva, 2002.

16 Polatajko HJ, Townsend EA, Craik J. Canadian Model of Occupational Performance and Engagement (CMOP-E). In: Townsend EA, Polatajko HJ (eds) Enabling Occupation II: Advancing an Occupational Therapy Vision of Health, Well-being, and Justice through Occupation. CAOT Publications ACE: Ottawa, ON, Canada, 2007, pp 22-36.

17 Whiteneck G, Meade MA, Dijkers M, Tate DG, Bushnik T, Forchheimer MB. Environmental factors and their role in participation and life satisfaction after spinal cord injury. Arch Phys Med Rehabil 2004; 85: 1793-1803.

18 Bhattacharyya J. Theorizing community development. Community Dev 2004; 34: 5-34.

19 Middleton JW, McCormick M, Engel S, Rutkowski SB, Cameron ID, Harradine P et al. Issues and challenges for development of a sustainable service model for people with spinal cord injury living in rural regions. Arch Phys Med Rehabil 2008; 89: 1941-1947.

20 Kendall M, Ungerer G, Dorsett P. Bridging the gap: transitional rehabilitation services for people with spinal cord injury. Disabil Rehabil 2003; 25: 1008-1015.

21 Hay-Smith EJ, Dickson B, Nunnerley J, Anne Sinnott K. 'The final piece of the puzzle to fit in': an interpretative phenomenological analysis of the return to employment in New Zealand after spinal cord injury. Disabil Rehabil 2013; 35: 1436-1446.

22 Miller WR, Rollnick S. Motivational Interviewing: Helping People Change. Guilford Press: New York, NY, USA, 2012.

23 Murphy GC. Putting a vocational focus back into rehabilitation. Aust J Career Dev 2009; 18: $36-44$.

24 AURIN. An introduction to statistical geography. 2014. Available at: http://docs.aurin. org.au/portal-help/select-your-area/an-introduction-to-statistical-geography/.

25 Jensen M, Karoly P. Self-report scales and procedures for assessing pain in adults. In: Turk D, Melzack R (eds) Handbook of Pain Assessment. Guildford Press: New York, USA, 1992, pp 135-151. 
26 Woolrich RA, Kennedy P, Tasiemski T. A preliminary psychometric evaluation of the hospital anxiety and depression scale (HADS) in 963 people living with a spinal cord injury. Psychol Health Med 2006; 11: 80-90.

27 Geyh S, Fellinghauer BA, Kirchberger I, Post MW. Cross-cultural validity of four quality of life scales in persons with spinal cord injury. Health Qual Life Outcomes 2010; 8: 1.

28 International Wellbeing Group Personal Wellbeing Index, 5th edn. Australian Centre on Quality of Life, Deakin University: Melbourne, VIC, USA, 2013.

29 Itzkovich M, Gelernter I, Biering-Sorensen F, Weeks C, Laramee M, Craven B et al. The spinal cord independence measure (SCIM) version III: reliability and validity in a multi-center international study. Disabil Rehabil 2007; 29: 1926-1933.

30 Kersten P, Cardol M, George S, Ward C, Sibley A, White B. Validity of the impact on participation and autonomy questionnaire: a comparison between two countries. Disabil Rehabil 2007; 29: 1502-1509.

31 Cardol M, de Haan RJ, de Jong BA, van den Bos GA, de Groot IJ. Psychometric properties of the impact on participation and autonomy questionnaire. Arch Phys Med Rehabil 2001; 82: 210-216.

32 Craig A, Nicholson Perry K, Guest R, Tran Y, Middleton J. Adjustment following chronic spinal cord injury: Determining factors that contribute to social participation. $\mathrm{Br} \mathrm{J}$ Health Psychol 2015; 20: 807-823.

33 Bates D, Machler M, Bolker B, Walker S. Fitting linear mixed-effects models using Ime4. J Stat Softw 2014; 67: 1-48.

34 R Development Core Team. R: A Language and Environment for Statistical Computing. The R Foundation for Statistical Computing: Vienna, Austria, 2008.
35 Murphy GC, O'Hare MA. The role of workplace social support in disability management. In: Geisen T, Harder HG (eds) Disabil Manag Workplace Integr Int Res Find. Gower, Farnham, Surrey, England, 2011.

36 Kennedy P. Coping effectively with spinal cord injuries. In: Craig A, Tran Y (eds) Psychological Aspects Associated with Spinal Cord Injury Rehabilitation. Nova: New York, NY, USA, 2008.

37 Murphy GC, O'Hare MA, Wallis L. The relationships among different types of social support accessed by traumatic spinal cord injury survivors. Int J Disabil Manage Res 2010; 5: 59-66.

38 Burns SM, Boyd BL, Hill J, Hough S. Psychosocial predictors of employment status among men living with spinal cord injury. Rehabil Psychol 2010; 55: 81-90.

39 Young AE, Murphy GC. Employment status after spinal cord injury (1992-2005): a review with implications for interpretation, evaluation, further research, and clinical practice. Int J Rehabil Res 2009; 32: 1-11.

40 Ferdiana A, Post MW, Hoekstra T, van der Woude LH, van der Klink JJ, Bultmann U. Employment trajectories after spinal cord injury: results from a 5-year prospective cohort study. Arch Phys Med Rehabil 2014; 95: 2040-2046.

41 Pollard C, Kennedy P. A longitudinal analysis of emotional impact, coping strategies and post-traumatic psychological growth following spinal cord injury: a 10-year review. Br J Health Psychol 2007; 12: 347-362.

42 Bickenbach J, Officer A, Shakespeare T, von Groote P. International Perspectives on Spinal Cord Injury. World Health Organization: Geneva, Switzerland, 2013. 